\title{
PENGUATAN LITERASI BERBASIS KEARIFAN LOKAL BAGI GURU DI SMA NEGERI 50 MALUKU TENGAH, KECAMATAN TELUK ELPAPUTIH, KABUPATEN MALUKU TENGAH
}

\author{
Mariana Lewier 1), Romilda Arivina da Costa 2) \\ Pendidikan Bahasa dan Sastra Indonesia, FKIP Universitas Pattimura, analewier@gmail.com \\ Pendidikan Bahasa dan Sastra Indonesia, FKIP Universitas Pattimura, ronaromilda70@ gmail.com
}

\begin{abstract}
Abstrak: Penguatan literasi di sekolah merupakan sebuah upaya yang dilakukan dengan melibatkan guru dan siswa secara menyeluruh dengan tujuan agar sekolah menjadi sebagai organisasi pembelajaran yang warganya literat secara sadar dan bertanggung jawab. Hal ini bersejalan dengan kemampuan yang diharapkan, yakni agar para siswa mampu mengakses, memahami, dan menggunakan sesuatu secara cerdas melalui berbagai aktivitas membaca, menulis, menyimak, dan berbicara. Berpijak dari realitas minimnya akses literasi yang berdampak pada rendahnya minat baca-tulis di masyarakat Indonesia, kegiatan pengadian kepada masyarakat ini difokuskan pada peningkatan kecapakan guru dan siswa dalam berliterasi yang berbasis pada kearifan lokal serta penekanan pada pentingnya literasi dalam bingkai etnokomunikasi. Kegiatan dalam bentuk ceramah diselingi pentas seni bahasa dan sastra ini diikuti oleh guru, siswa, dan komunitas seni SMA Negeri 50 Maluku Tengah. Hasil yang dicapai menyasar pada pemahaman dan penyeragaman persepsi tentang pentingnya penguatan literasi dengan menjadikan guru sebagai pionir literasi di sekolah. Para peserta mendapatkan pengetahuan dan pengalaman baru dalam hal alih wahana serta konsep etnokomunikasi sehingga mampu mengeksplorasi kekayaan budaya lokal sebagai wujud jati diri yang mengandung beragam kearifan lokal.
\end{abstract}

Kata kunci: penguatan literasi, kearifan lokal, etnokomunikasi

Abstract: Strengthening literacy in schools is an effort made by involving teachers and students as a whole with the aim that schools become learning organizations whose citizens are literate consciously and responsibly. This is in line with the expected abilities, namely so that students are able to access, understand, and use things intelligently through various reading, writing, listening, and speaking activities. Based on the reality of the lack of access to literacy which has an impact on the low interest in reading and writing in Indonesian society, this community service activity is focused on increasing the skills of teachers and students in literacy based on local wisdom and emphasizing the importance of literacy in an ethnocommunication frame. The activity in the form of lectures interspersed with language and literary arts performances was attended by teachers, students, and the arts community of SMA Negeri 50 Central Maluku. The results achieved are aimed at understanding and uniform perception of the importance of strengthening literacy by making teachers as literacy pioneers in schools. The participants gained new knowledge and experience in terms of vehicle transfer and the concept of ethnocommunication so that they were able to explore the richness of local culture as a form of identity that contains a variety of local wisdom.

Keywords: literacy strengthening, local wisdom, ethnocommunication

\section{PENDAHULUAN}

Program literasi (membaca-menulis) merupakan salah satu aspek penting dalam proses pendidikan. Kesadaran akan pentingnya budaya literasi dinyatakan pula oleh UNESCO yang menggarisbawahi 
kemampuan literasi (literary skills) sebagai dasar pembelajaran abad ke-21. Data statistik UNESCO tahun 2012 menyebutkan indeks minat baca Indonesia baru mencapai 0,001. Artinya, setiap 1.000 penduduk, hanya satu orang saja yang memiliki minat baca. Kenyataan bahwa minat baca-tulis masyarakat Indonesia masih rendah telah mendorong Kementerian Pendidikan dan Kebudayaan menggagas Gerakan Literasi Nasional yang ditetapkan dalam Permendikbud Nomor 23 Tahun 2015. Gagasan ini diarahkan pada penumbuhan budi pekerti anak melalui budaya literasi di seluruh pelosok Indonesia.

Literasi sekolah dalam konteks GLS (Gerakan Literasi Sekolah) adalah kemampuan mengakses, memahami, dan menggunakan sesuatu secara cerdas melalui berbagai aktivitas, antara lain membaca, melihat, menyimak, menulis, dan/ atau berbicara (Kemendikbud, 2016a: 6). Hal ini kemudian diwujudkan pula melalui program penguatan literasi sekolah dan masyarakat yang digagas oleh P4TK Bahasa Kemdikbud pada 2020 (https://p4tkbahasa.kemdikbud.go.id/2020/05/30/program-penguatan-literasisekolah-dan-masyarakat/) yang salah satu tujuan mendasarnya adalah menumbuhkan sikap ingin tahu dan cinta pengetahuan.

Dalam lima tahun terakhir ini, menurut Purwanti (2021), terjadi peningkatan indeks literasi baca masyarakat di Indonesia. Hal ini dibuktikan melalui Survei Indeks Perpustakaan Nasional RI di 102 kabupaten/kota pada 34 provinsi yang menunjukkan nilai Indeks Kegemaran Membaca tahun 2016 masih 26,5 (sesuai target yang ditetapkan) dan pada tahun 2020 melonjak menjadi 55,74 (melampaui target 55,3). Namun, kajian terkait Aktivitas Literasi membaca (Alibaca) yang dilakukan oleh Badan Penelitian dan Pengembangan Kementerian Pendidikan dan Kebudayaan tahun 2019 menunjukkan bahwa nilai Indeks Alibaca Indonesia tahun 2018 masih kategori rendah, yakni 37,22. Salah satu faktor penyebabnya adalah pada dimensi akses. Dimensi akses meliputi ketersediaan perpustakaan (sekolah, umum, komunitas), tenaga pengelola perpustakaan, dan perilaku membeli surat kabar, majalah, maupun tabloid.

Berdasarkan survei awal secara daring dengan pihak SMAN 50 Maluku Tengah, ditemukan bahwa masalah literasi di sekolah perlu ditingkatkan dan ditata lebih baik lagi. Sebelum masa Pandemi Covid, pihak sekolah telah melaksanakan program literasi 15 menit membaca di kelas yang dijadwalkan setiap Senin, tetapi kurang diperhatikan dan tidak maksimal. Kemudian, dilakukan upaya untuk membawa buku-buku cerita ke sekolah dan mendirikan ruang baca di kantor guru. Namun, karena muncul Covid-19, rencana ini tidak dapat diwujudkan. Selain itu, siswa kebih tertarik membaca karya sastra (novel dan cerita rakyat), tetapi ketersediaannya sangat terbatas di ruang baca/perpustakaan sekolah.

Persoalan yang dihadapi di SMAN 50 Maluku Tengah ini tentu menjadi salah satu potret dari program literasi sekolah di Maluku yang belum maksimal dan tertata dengan baik. Literasi anak dan generasi muda Maluku haruslah menempati skala prioritas dalam rangka menumbuhkembangkan sikap kritis dan mengembangkan wawasan berpikir yang luas sejak dini. Pembelajaran abad 21 bahkan menekankan pada pembelajaran multiliterasi yang bermuara pada kecakapan multidimenasi dalam 
mengaplikasikan berbagai ilmu pengetahuan dan pembelajarannya (Abidin, 2014). Oleh karena itu, penguatan literasi dapat diarahkan pada peningkatan kecakapan dan kepribadian siswa. Salah satunya dengan berbasis pada kearifan lokal, khususnya yang berkaitan dengan nilai-nilai budi pekerti yang perlu dimiliki siswa.

Kegiatan penguatan literasi berbasis kearifan lokal yang dilakukan di SMAN 50 Maluku Tengah mengarah pada pembentukan karakter peserta didik. Fajarini (2014: 123-124) memaparkan bahwa kearifan lokal adalah pandangan hidup dan ilmu pengetahuan serta berbagai strategi kehidupan yang berwujud aktivitas yang dilakukan oleh masyarakat lokal dalam menjawab berbagai masalah dalam pemenuhan kebutuhan mereka. Dalam bahasa asing sering juga dikonsepsikan sebagai kebijakan setempat "local wisdom" atau pengetahuan setempat "local knowledge" atau kecerdasan setempat "local genious". Dengan demikian, kearifan lokal yang menjadi pegangan hidup masyarakat hingga kini harus dieksplorasi khususnya dalam dunia pendidikan sehingga menghasilkan generasi yang cerdas, bijaksana, dan berkarakter. Kearifan lokal ini dapat diintegrasikan, baik dalam pembelajaran pada setiap mata pelajaran maupun dalam gerakan literasi sekolah.

Salah satu langkah yang akan dilakukan oleh tim pelaksana pengabdian adalah mendorong minat baca siswa dengan cara memperkenalkan bacaan-bacaan yang dekat dengan kehidupan mereka sebelum kemudian didorong untuk mengembangkan wawasan dari sumber bacaan yang lebih luas dan global. Penguatan literasi berbasis kearifan lokal diharapkan dapat menjawab tantangan pembelajaran abad ke-21 sebagaimana ungkapan "berpikir global, bertindak lokal”.

Menurut Sibarani (2012), kearifan lokal adalah suatu bentuk pengetahuan asli dalam masyarakat yang berasal dari nilai luhur budaya masyarakat setempat untuk mengatur tatanan kehidupan masyarakat. Secara konseptual, kearifan lokal merupakan kekayaan budaya lokal yang mengandung kebijakan hidup; pandangan hidup (way of life) yang berlaku pada sekelompok masyarakat tertentu. Hal ini kemudian mewujud pada nilai, norma, etika, kepercayaan, adat istiadat, hukum adat, dan aturan-aturan khusus. Namun, budaya masyarakat bukanlah warisan yang statis karena terkandung kekuatan yang dapat diberdayakan untuk menghadapi dunia baru di era digital ini.

Friedman dalam (Alwasilah, 2009: 3-4) menyatakan bahwa globalisasi tahap ketiga yang berawal dari tahun 2000, dipicu oleh semakin meluasnya penggunaan internet, dan sistem perdagangan elektronis (e-commerce). Globalisasi mutakhir ini membawa manusia pada kemajuan pesat dalam bidang teknologi informasi dan komunikasi. Pengaruh globalisasi ini segera menyusup ke semua lini kehidupan, termasuk pendidikan dan etnokomunikasi.

Dalam lingkup ilmu bahasa atau atau linguistik, etnokomunikasi seyogianya dipandang sebagai salah satu varian atau cabang sosiolinguistik. Cabang ini mengolaborasikan bidang etnografi dan komunikasi. Istilah etnokomunikasi itu sendiri digagas oleh Dell Hymes, dan pertama kali disajikan 
dalam bentuk sebuah pendekatan yang digunakan untuk mengkaji penggunaan bahasa secara umum, terkait dengan nilai sosial dan budaya. Selanjutnya, etnokomunikasi lebih difokuskan pada situasi, penggunaan, pola, dan fungsi berbahasa sebagai sebuah aktivitas tersendiri. Bertolak dari konsentrasi tersebut, etnokomunikasi kemudian didefinisikan sebagai pengkajian peranan bahasa dalam perilaku komunikasi suatu masyarakat; cara bahasa digunakan dengan beragam kebudayaannya.

Hasanuddin, dkk. (dalam Anshori, 2017: 35) menyebutkan bahwa pada dasarnya etnokomunikasi memusatkan perhatian pada pola komunikasi dalam beragam masyarakat bahasa. Pola komunikasi dimaksud sebenarnya adalah pola penggunaan bahasa seseorang atau sebuah komunitas. Pola tersebut terbentuk karena adanya faktor budaya yang mempengaruhi cara mereka berkomunikasi.

\section{METODE}

Kegiatan pengabdian ini dilaksanakan dengan menggunakan metode dengan tahapan sebagai berikut.

1. Tahap Awal/Observasi

Pada tahap awal ini, dilakukan pendataan informasi kondisi sekolah dan pelaksanaan program literasi di sekolah sasaran/pihak mitra kegiatan dengan cara melakukan wawancara jarak jauh dengan salah satu guru yang merupakan alumni Prodi PBSI FKIP Unpatti. Selanjutnya, penentuan Tim Pengabdian berdasarkan bidang kepakaran dan kesesuaian dengan masalah yang dihadapi terkait program literasi, yakni bidang kepakaran sastra dan bidang kebahasaan/linguistik. Pada tahap persiapan ini, Tim berkoordinasi dengan pihak mitra mengenai tanggal dan waktu pelaksanaan kegiatan pengabdian.

2. Tahap Pelaksanaan

Tim Pengabdian melaksanakan kegiatan di SMA Negeri 50 Maluku Tengah Kecamatan Teluk Elpaputih, Kabupaten Maluku Tengah pada Rabu, 4 Agustus 2021 dengan metode ceramah yang disampaikan oleh kedua anggota tim sesuai materi berdasarkan bidang keahlian masing-masing, yaitu kesastraan (sastra lokal/tradisi lisan) dan kebahasaan (etnokomunikasi). Peserta kegiatan meliputi para guru dan siswa, serta Komunitas Mata Bambu binaan sekolah. Kegiatan dibuka oleh Kepala SMA Negeri 50 Maluku Tengah yang merespons dengan sangat baik kegiatan ini.

3. Tahap Pelaporan

Tahapan ini meliputi penyampaian laporan kegiatan yang disampaikan secara tertulis kepada Pimpinan FKIP, termasuk laporan penggunaan dana sesuai realisasi anggaran.

4. Tahap Publikasi

Tahapan publikasi merupakan bagian dari pertanggungjawaban terhadap kegiatan yang telah dilakukan, berupa publikasi luaran kegiatan, baik luaran wajib maupun luaran tambahan, yakni 
artikel pada jurnal ilmiah PkM dan dokumentasi kegiatan. Diharapkan dari publikasi ini dapat memicu peningkatan literasi di sekolah lainnya.

\section{HASIL DAN PEMBAHASAN}

Adilangkah pelaksanaan PKM ini adalah mendorong minat baca siswa dengan cara mengenalkan bacaan-bacaan yang dekat dengan kehidupan mereka sebelum didorong lebih jauh untuk mengembangkan wawasan dari sumber bacaan yang lebih luas dan global. Langkah ini ditempuh mengingat sekolah atau lembaga pendidikan formal yang ada di wilayah tersebut dapat menjadikan kearifan lokal setempat sebagai rujukan untuk membentuk kultur sekolah sehingga peserta didik tidak terasing dari budaya yang melingkupinya. Dikatakan demikian karena keterasingan peserta didik dengan lingkungan budayanya memang sementara bergerak ke titik yang memprihatinkan. Salah satu penyebabnya adalah kederasan arus budaya luar yang membanjiri, bahkan meluap ke seluruh pelosok tanah air.

Ketika sedang menikmati kudapan sambil berdiskusi dengan salah seorang guru pengerak Komunitas Mata Bambu di SMA Negeri 50, nama komunitas tersebut justru menginspirasi wujud kearifan lokal yang menarik untuk dibicarakan. Nama komunitas di sekolah itu menggunakan kompositum bahasa Melayu Ambon (disingkat BMA), dan bukan salah satu bahasa lokal yang hidup di daerah itu. Dalam BMA, kata bambu juga bersinonimi dengan kata bulu. Akan tetapi, kata bambu-lah yang dipilih. Padahal, dalam pembentukan kompositumnya, kedua kata ini pun dapat dipadukan dengan kata mata. Jadi, ada kompositum mata bambu, ada pula mata bulu. Kemungkinan besar, kedua objek itu memiliki referensi yang berbeda. Semua peserta kegiatan ini rupanya baru menyadari hal tersebut. Diduga kuat, objek yang sudah terlalu akrab dengan kehidupan, pada dasarnya sudah dianggap biasa, dan hampir tidak terlihat keistimewaannya. Ibarat rutinitas yang tidak lagi menggairahkan.

Gambaran akan diksi bulu dan bambu yang mengacu pada tumbuhan berumpun, yang batangnya bundar berongga itu kemudian diskemakan sebagai berikut. 


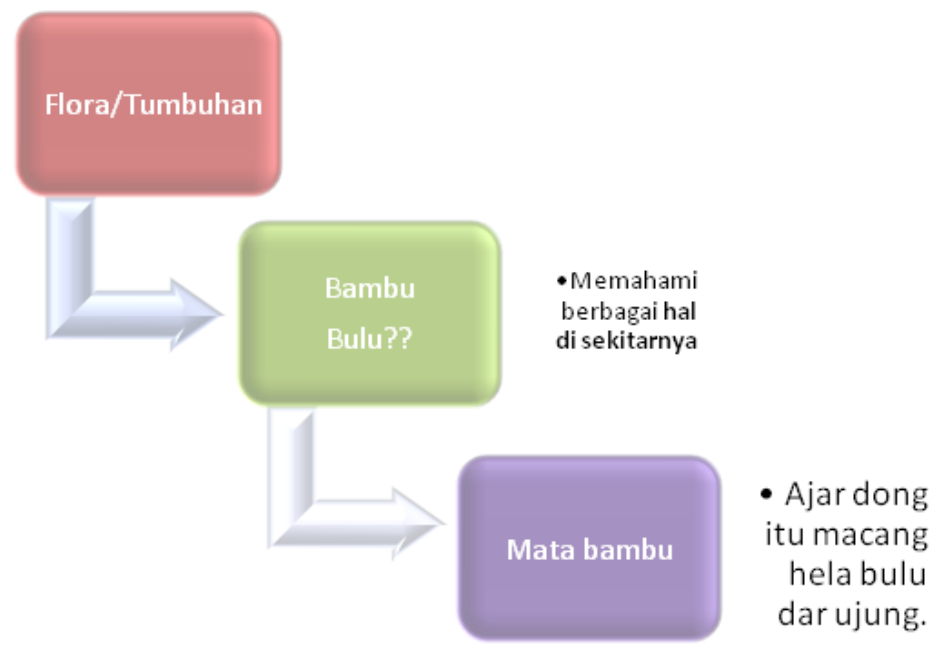

Melalui KBBI, entri bambu juga disinonimkan dengan entri buluh. Namun, jenis bambu lebih banyak dibandingkan dengan jenis buluh dalam konsep tumbuhan. Penamaan komunitas dengan kompositum mata bambu mengindikasikan bahwa bambu lebih lazim dikenal oleh para guru dan peserta didiknya daripada bulu.

Dengan terkuaknya sinonimik kata bambu dan bulu yang selama ini kurang disadari, para guru dan peserta didik dapat menempuh minimal dua jalur untuk mencari tahu jawabannya lebih jauh. Pertama, mereka dapat membincangkan perbedaannya dengan masyarakat petani setempat yang bekerja di hutan ataupun dengan generasi tua yang biasanya lebih memahami lingkungan alam. Rasa penasaran itu mungkin akan terobati dengan dibentangkannya berbagai jenis bambu juga bulu, lengkap dengan fungsinya masing-masing, serta produk yang dapat dihasilkan. Misalnya, mebel, peralatan dapur, bahan bangunan, atau alat musik. Kedua, mereka dapat mengakses website Museum Siwalima ataupun mengunjunginya kelak. Mengapa museum yang direkomendasikan pada kesempatan PKM ini? Karena museum bukanlah sebuah tempat penyimpanan benda-benda kuno semata-mata, melainkan juga tempat konservasi penyimpan informasi ilmiah yang direpresentasikan atau diwujudkan melalui benda-benda budaya. Pada website Museum Siwalima, para guru dan peserta didik bisa mendapatkan informasi mengenai jenis-jenis suling bambu sebagai salah satu alat musik tradisional. Salah satu tempat asal suling bambu koleksi Museum Siwalima adalah Desa Tihulale di Seram Bagian Barat (SBB). Berdasarkan informasi tersebut, para peserta didik pun dapat memburu informasi mengenai jenis bambu yang dapat dijadikan bahan baku untuk membuat suling, dan alasan ilmiahnya.

Secara tidak langsung, jalur pertama akan menjelmakan materi budaya dan kearifan lokal sebagai jembatan antargenerasi karena alternatif untuk membincangkan hal-ikhwal mata bambu dengan generasi yang lebih tua itu ibarat mengembalikan kebiasaan bertutur generasi tua kepada generasi muda (anakcucu). Jalur ini pun akan membuka kembali ruang untuk mengarahkan generasi milenial yang cenderung 
menjadi pengguna (user) budaya dari luar agar tidak mengabaikan kecerdasan dan kearifan lokal (local genius atau local wisdom) yang ada di sekeliling mereka. (Anshori, 2017: 121). Pola komunikasi yang lahir dari aktivitas semacam ini bukan lagi komunikasi searah dari generasi tua kepada generasi muda, melainkan komunikasi timbal balik dari generasi muda kepada generasi tua dan sebaliknya.

Selanjutnya, jalur kedua direkomendasikan karena dengan bersandar pada budaya lisan sebagai sumber utama informasi, jangkauan pengetahuan seseorang akan sangat terbatas. Petutur atau pendengar hanya memperoleh informasi dari sumber yang berada di dekatnya. Dengan sendirinya, informasi lain yang tidak terjangkau, tidak dapat dikuasai. Jalur ini pun lebih lebih efektif dan efisien sejalan dengan konsep literasi baik, secara mikro yang mengacu pada kemampuan membaca dan menulis, maupun secara makro yang berarti melek teknologi, politik, berpikir kritis, dan peka terhadap lingkungan sekitar. Malahan jalur ini dapat mengantarkan para guru dan peserta didik untuk mencapai kemampuan mengolah informasi dan pengetahuan untuk kecakapan hidup. Mereka dapat memulainya dengan membudidayakan bambu atau bulu jenis tertentu, dan mengkreasikan bahan-bahan tersebut menjadi komoditi yang bernilai jual tinggi.

Berkaitan dengan penguatan literasi berbasis kearifann lokal, diharapkan guru menjadi pionir literasi. Artinya, guru pionir literasi harus mampu menjadi teladan bagi guru lainnya. Guru penggerak literasi di sekolah tetap menghidupkan ruh literasi di kalangan peserta didiknya. Maksud literasi di sini tidak hanya identik dengan membaca buku saja, tetapi dalam konteks yang lebih luas, termasuk literasi berbasis kearifan lokal.

Satu langkah yang penting dalam upaya menjaga sastra daerah/lokal sebagai sumber ilmu pengetahuan pada masa sekarang dan akan datang adalah perubahan dalam sistem pewarisannya. Pewarisan secara konvensional, umumnya bersifat vertikal. Namun, pada masa sekarang, pewarisan dapat dilakukan dengan cara alih wahana. Beberapa contoh alih wahana yang dapat dilakukan adalah:

a. bentuk lisan ke bentuk tulisan;

b. cerita tertulis ke pentasan (novel ke film/sinetron/teater/tari/opera);

c. cerita lisan ke pentasan teater/sendratari; atau

d. puisi rakyat (kapata) ke novel/film.

Perlu disadari bahwa karya sastra lokal memberi kemungkinan menghidupkan kearifan lokal, yaitu memelihara, mengembangkan, mentransformasi berbagai bentuk tradisi/kultur masyarakat lokal. Siswa dapat diarahkan untuk mengeksporasi diksi yang berakar pada tradisi dalam beragam rasa dan nuansa makna. Dengan demikian, siswa telah digiring untuk menjadi agen representasi dari ekspresi budaya masyarakatnya. 


\section{KESIMPULAN}

Berdasarkan hasil pelaksanaan kegiatan Pengabdian kepada Masyarakat (PkM) ini, dapat disimpulkan beberapa hal sebagai berikut.

1. Gerakan literasi di sekolah, termasuk di SMA Negeri 50 Maluku Tengah merupakan suatu aktivitas yang menyumbang banyak manfaat bagi terciptanya siswa-siswa yang cerdas, kreatif, dan berkarakter. Penguatan literasi yang berbasis pada kearifan lokal perlu dilakukan oleh para guru agar nilai-nilai budaya lokal dapat tersentuh dan terwariskan kepada para generasi muda.

2. Pengenalan akan nilai-nilai kearifan lokal dapat dijembatani dengan menekankan pentingnya berkomunikasi dan bagaimana cara penyampaian bahasa. Hal ini dapat dikenali melalui bidang ilmu etnokomunikasi.

3. Komunitas Seni yang telah dibentuk oleh SMA Negeri 50 Maluku Tengah dapat menjadi energi penggerak yang menguatkan pelaksanaan gerakan literasi di sekolah.

\section{REFERENSI}

Abidin, Yunus. 2015. Pembelajaran Multiliterasi. Bandung : PT Refika Aditama.

Anshori, Dadang S. 2017. Etnografi Komunikasi: Perspektif Bahasa. Jakarta: Rajawali Press.

Fajarini, U. 2014. “Peranan Kearifan Lokal dalam Pendidikan Karakter”. Sosio Didaktika. 1

(2): 123-130. Tersedia pada http://journal.uinjkt.ac.id/index. php/ SOSIO-

FITK/article/view/1225/1093. Diakses pada tanggal 6 Maret 2020.

Kemendikbud. 2016a. Panduan Gerakan Literasi Sekolah di Sekolah Dasar. Jakarta: Direktorat Jenderal Pendidikan Dasar dan Menengah.

Purwanti. Agustina. 2021. "Kemudahan Akses dan Budaya Membaca Ungkit Literasi” dalam Harian Kompas, Minggu, 4 April 2021 hal. 4.

Sibarani, Robert, 2012. Kearifan Lokal: Hakikat, Peran, dan Metode Tradisi Lisan. Jakarta: Asosiasi Tradisi Lisan.

Wardhaugh, Ronald. 2002. An Introduction to Sociolinguistics. Fourth Edition. Oxford: Blackwell Publishers.

https://kumparan.com/lenteramaluku/literasi-di-maluku-tertinggal-begini-tanggapan-kepala-kantorbahasa-1553934479439102297/full

https://p4tkbahasa.kemdikbud.go.id/2020/05/30/program-penguatan-literasi-sekolah-dan-masyarakat/ http://riset.unisma.ac.id/index.php/NOSI/article/view/4 
https://sinaukomunikasi.wordpress.com/2013/10/31/apa-itu-etnografi-komunikasi/ 